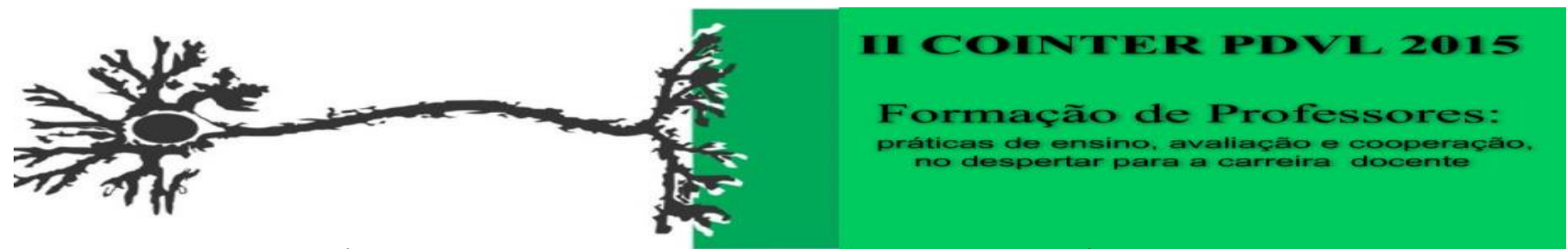

\title{
O USO DE TEMÁTICAS AMBIENTAIS NO ENSINO DE QUÍMICA PARA TURMAS DE JOVENS E ADULTOS DO ENSINO MÉDIO
}

\author{
Apresentação: Comunicação Oral \\ Emerson Gonçalves Moreira ${ }^{1}$; Flávia Rhuana Pereira Sales ${ }^{2}$; Luís Victor dos Santos Lima ${ }^{3}$ \\ Alessandra Marcone Tavares Alves de Figueirêdo ${ }^{4}$
}

\section{Resumo}

Em grande parte dos lares brasileiros, o óleo vegetal é um produto bastante utilizado no preparo de alimentos e, quando descartado de forma inadequada, apresenta-se como um grave poluente ao meio ambiente contaminando de forma direta os lençóis freáticos e gerando consequências irreversíveis quando descartados no solo. Diante disso, é necessário conscientizar a comunidade sobre as consequências ambientais geradas e construir possibilidades de sua reciclagem. Neste sentido, o conhecimento químico deve possibilitar os discentes a compreensão dos processos químicos e do mesmo modo suas implicações, ambientais, sociais e políticas. A abordagem desta temática no ensino de Química é de suma importância, uma vez que desperta uma conscientização ambiental nos discentes com um descarte adequado do óleo de fritura e, ainda, pontua os problemas de saúde que podem ocorrer devido ao consumo de alimentos que são preparados com excesso de óleo de soja. Assim sendo, o objetivo deste trabalho é expressar o resultado da análise de um questionário e de discussões em sala de aula sobre o uso, descarte e reutilização do óleo vegetal nas residências dos alunos de uma turma do $2^{\circ}$ ano do Ensino Médio na modalidade de Educação de Jovens e Adultos (EJA), de um estabelecimento estadual de ensino situado no município de Santa Rita, no estado da Paraíba. A metodologia utilizada foi embasada nas pesquisas qualitativa, quantitativa e participante. Os resultados apontaram para um consumo excessivo do óleo de soja, além disso, uma falta de conhecimento sobre o descarte, reutilização e postos de coletas para estes resíduos.

Palavras-Chave: Ensino de Química, Educação Ambiental, EJA.

\section{Introdução}

Segundo a Ecóleo (2013), o Brasil produz 9 bilhões de litros de óleos vegetais anualmente, e a terça parte corresponde a óleos comestíveis, configurando um consumo per capita de 20 litros anuais, o que resulta em uma produção de 3 bilhões de litros de óleo por ano no país. Estimativas apontam que o montante coletado de óleos vegetais usado no país corresponde a menos de $1 \%$ do total produzido, ou seja, 6 milhões e meio de litros de óleos usados.

O óleo vegetal é um produto utilizado largamente no preparo de alimentos e, quando descartado de modo impróprio, constitui-se em um grave poluente. Braga (2007) afirma que, um litro de óleo poderia contaminar até um milhão de litros de água potável, um gesto nocivo que afeta

\footnotetext{
${ }^{1}$ Graduando em Licenciatura em Química, IFPB, emergmoreira@gmail.com

${ }^{2}$ Graduando em Licenciatura em Química, IFPB, flavia.rhuana@outlook.com

${ }^{3}$ Mestrando em Ensino de Ciências, UFRN, luisvictor_quim@hotmail.com

${ }^{4}$ Doutora em Química, IFPB, alessatavares@yahoo.com.br
} 
a qualidade da água, especialmente a potável, que vem decaindo globalmente. Os danos causados pelo óleo de cozinha usado têm tomado várias dimensões, já que o descarte de óleo residual de frituras em pias ou no solo acaba provocando sérios danos ambientais, várias entidades governamentais ou não, buscam soluções e adotam medidas para alterar esse comportamento.

Além da qualidade ambiental, o consumo do óleo de cozinha está associado a questões de saúde. Nos últimos anos, diante das mudanças nos padrões alimentares e no estilo de vida da sociedade, o crescente consumo de frituras e gorduras tem sido questionado, tendo em vista a associação entre consumo excessivo e o aumento na ocorrência de dislipidemias e doenças cardiovasculares. (TOMASI et al, 2014).

É necessário trazer esse tipo de temática para as salas de aula, visto que o Ensino de Química e a Educação Ambiental interligados ampliam as informações a respeito das problemáticas ambientais e, ainda, assinala para diversas soluções. Destarte, o professor de Química deve utilizar dessas temáticas em sua aula, conforme os Parâmetros Curriculares Nacionais (PCNs, 2002, p. 26), a associação de temas "atuais" com o ensino de Química pode ser vista como questões que fazem parte de "processos que estão sendo intensamente vividos pela sociedade, pelas comunidades, pelas famílias, pelos alunos e educadores em seu cotidiano".

Nessa perspectiva, o objetivo desse trabalho é investigar de que maneira é feito o descarte do óleo residual, bem como o consumo de óleo de soja, nas residências dos discentes do $2^{\circ}$ ano do Ensino Médio na modalidade de Educação de Jovens e Adultos. A abordagem desta temática no ensino de Química é de suma importância, uma vez que desperta uma conscientização ambiental nos discentes com um descarte adequado do óleo de fritura e, ainda, pontua os problemas de saúde que podem ocorrer devido ao consumo de alimentos que são preparados com excesso de óleo de soja.

Para o desenvolvimento dessa ação, a pesquisa participante será utilizada, além das pesquisas qualitativa e quantitativa. Para tal, será entregue um questionário com questões que discorrem sobre a temática supramencionada e, além disso, debates em sala de aula serão realizados com o intuito de elucidar a problemática lançada.

\section{Fundamentação Teórica}

O ensino de Química atual tem se reduzido a simples transmissão de informações, sem qualquer relação com o cotidiano do aluno, exigindo deste quase sempre a pura memorização, restrita a baixos níveis cognitivos o que, consequentemente, não favorece uma aprendizagem significativa (BRASIL, 2006). Muito se discute a respeito da reconfiguração do modelo de ensino 
atual (tecnicista e tradicional) a um modelo mais participativo, com autonomia e que seja críticoreflexivo. Alguns fatores definem a qualidade do ensino e, por muitas vezes, são desconsiderados, tendo como exemplo, a deficiência no eixo pedagógico na formação inicial e continuada de professores como afirma Silva et. al. (2012) “o modelo de formação que tem prevalecido em nosso sistema educativo, principalmente na área das Ciências Exatas, está pautado no aprofundamento de áreas específicas que não seja do "saber ensinar."

Uma aprendizagem significativa no ensino de Química deve abranger temáticas relacionadas à vivência e aos conhecimentos prévios dos discentes da EJA e, mais do que isso, o aprendizado da disciplina de Química “deve possibilitar ao aluno a compreensão tanto dos processos químicos em si quanto da construção de um conhecimento científico em estreita relação com as aplicações tecnológicas e suas implicações ambientais, sociais, políticas e econômicas” (PCNEM, 1999, p. 31).

Partindo dessa premissa, a abordagem de temáticas que envolvam o meio ambiente e a saúde pública, corrobora para uma aprendizagem significativa, principalmente para alunos da Educação de Jovens e Adultos, os quais:

[...] caracterizam-se por pertencer a uma população com faixa etária adiantada em relação ao nível de ensino demandado, constituindo um grupo populacional que tem sido reconhecido como integrante da chamada "distorção série-idade". [...] Esses sujeitos são portadores de saberes produzidos no cotidiano e na prática laboral. Formam grupos heterogêneos quanto à faixa etária, conhecimentos e ocupação (trabalhadores, desempregados, atuando na informalidade). Em geral, fazem parte de populações em situação de risco social e/ou são arrimos de família, possuindo pouco tempo para o estudo fora da sala de aula. (BRASIL, 2009, p. 44-45).

Dessa forma, levando em consideração os conhecimentos prévios trazidos pelos jovens e adultos, utilizar temáticas ambientais torna-se um recurso importantíssimo, uma vez que contribuem para o processo de aprendizagem visando possibilitar ao aluno perceber que a ciência é uma forma diferenciada de explicar aspectos do cotidiano (SASSI; LINDEMANN, 2013). Essa importância também é apontada nos Parâmetros Curriculares Nacionais (PCNs), pois a inclusão de temas transversais, como Meio Ambiente, colabora na superação dos problemas ambientais, pela conscientização e sensibilização das novas gerações, quanto às consequências maléficas ao ambiente, que podem ser evitadas pela mudança das ações humanas. (BRASIL, 1998).

Dentro dessa conjuntura, o desenvolvimento de uma práxis que priorize questões ambientais, como o consumo/descarte do óleo de soja usado, contribuirá para o fortalecimento de uma aprendizagem significativa no ensino de Química, tal aprendizagem é exacerbada quando se leva em conta o saber popular dos alunos pertencentes a modalidade da EJA.

\section{Metodologia}


Para o desenvolvimento deste trabalho foi utilizada a pesquisa participante que, segundo Severino (2008, p. 120), é definida como "aquela em que o pesquisador, para realizar a observação dos fenômenos, compartilha a vivência dos sujeitos pesquisados, participando, de forma sistemática e permanente, ao longo do tempo da pesquisa, das suas atividades".

As pesquisas qualitativa e quantitativa também foram utilizadas, a primeira "caracteriza-se pelo enfoque interpretativo, tendo como premissas a observação das ações humanas e sua interpretação, a partir do ponto de vista das pessoas que praticam as ações". (TEIS; TEIS, 2013, p. 1). Enquanto que a segunda, "se constitui em quantificar dados obtidos através de informações coletadas por meio de questionários, entrevistas, observações e utilização de técnicas estatísticas”. (OLIVEIRA, 2008, p. 62).

A pesquisa ocorreu na escola Estadual Maria de Lourdes, localizada na cidade de Santa Rita, estado da Paraíba no Brasil, com duas turmas do $2^{\circ}$ ano do Ensino Médio da Educação de Jovens e Adultos, no turno da noite. Quarenta e um alunos participaram de todos os momentos deste ensaio. Foram necessárias 3 (três) aulas de 30 minutos cada. O desenvolvimento desta práxis se deu com a aplicação de um questionário estruturado contendo 7 (sete) questões (Anexo I), as quais versavam sobre o consumo do óleo vegetal e o descarte do óleo de cozinha residual. Após esta etapa, houve uma discussão baseada nos questionários e em cima da temática trabalhada.

\section{Resultados e Discussão}

A pesquisa realizada em sala de aula para se estimar o consumo do óleo vegetal de cozinha e o descarte do óleo residual, pelos discentes da EJA, foi de fundamental importância para identificar os hábitos alimentares e a consciência ambiental desses estudantes.

Com base no questionário supracitado, foi possível construir gráficos a partir das respostas fornecidas pelos alunos o que gerou um melhor entendimento da problemática. Desta forma, no Gráfico 1 buscou-se analisar a frequência do consumo do óleo vegetal nas residências destes alunos.

Gráfico 1 - Qual o consumo de óleo vegetal em sua residência? Fonte: Própria.

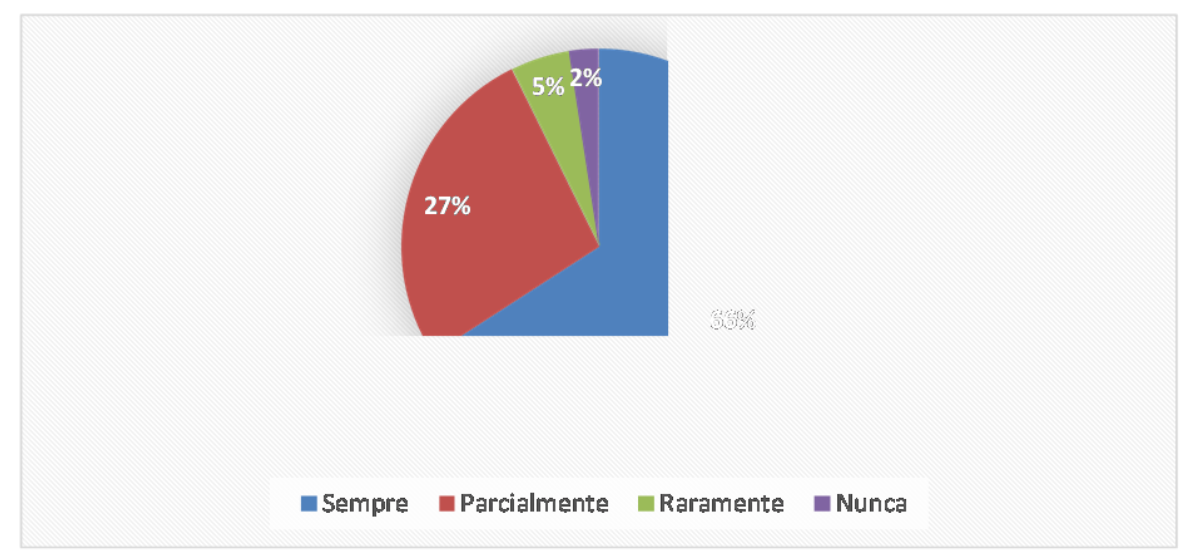


Observa-se no Gráfico 1, que 66\% dos discentes consomem óleo vegetal com uma frequência muita alta. Pelo exposto, verifica-se que o consumo de óleo pelos alunos e suas famílias é superior às recomendações feitas nas diretrizes de alimentação saudável elaborada pelo Ministério da Saúde no ano de 2006, o qual sugere 900 mL de óleo ao mês para uma família de quatro pessoas para todas as preparações. (BRASIL, 2006).

Essa primeira pergunta gerou um debate, com um novo questionamento, que discorreu sobre: Em qual finalidade vocês utilizam o óleo? Diante das respostas, observou-se que $93 \%$ dos discentes o utilizam apenas no processo de fritura de alimentos. Considerando-se que $93 \%$ dos entrevistados relataram o emprego do óleo no processo de frituras, há uma coerente correspondência com o elevado consumo de óleo ilustrado no Gráfico 1.

Em alusão ao Gráfico 2, o qual ilustra a reutilização do óleo de cozinha para o preparo de alimentos, percebe-se que quase metade dos discentes reutilizam o óleo para mais de uma preparação.

Gráfico 2 - Você reaproveita o óleo de soja (usado) para mais de uma preparação? Por quê? Fonte: Própria.

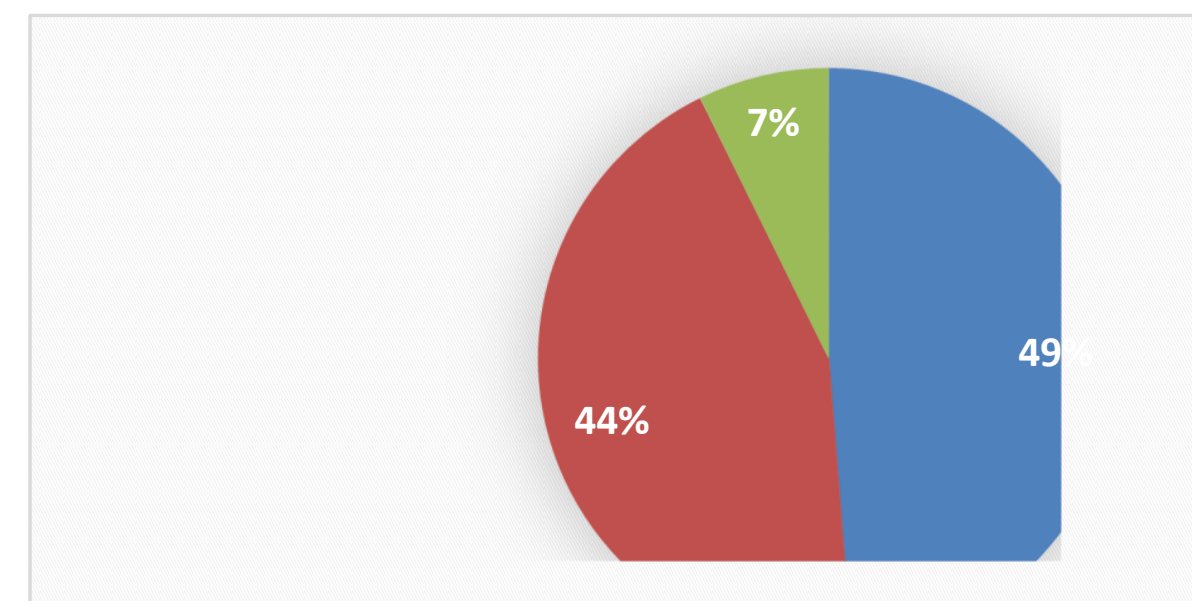

Para que o óleo seja benéfico, é necessário que ele esteja em bom estado de conservação, uma vez que óleos degradados têm efeito contrário à saúde, desencadeiam inúmeras complicações ao organismo humano (LIMA; GONÇALVES, 1997).

Nesta mesma pergunta do Gráfico 2, foi solicitado aos alunos que justificassem o porquê de reutilizar ou não o óleo de soja, como justificativa alguns alunos disseram:

Aluno 1 - "Sim, pois economiza para outra fritura";

Aluno 2 - "Sim, porque já é costume de casa";

Aluno 3 - "Não, porque ele fica com uma cor diferente e na minha opinião ele não dá para ser reaproveitado, pois perde a consistência";

Aluno 4 - "Não, porque o óleo de soja solta substâncias químicas". 
No momento de discussão em sala sobre esse questionamento, vários estudantes afirmaram que alguns estabelecimentos comerciais no entorno da escola, reutilizam o óleo constantemente, como afirma um dos discentes:

Aluno 5 - "Na mulher do pastel aí na frente professor, o óleo parece que não é trocado nunca, tem uma cor tão estranha”.

$\mathrm{Na}$ análise do Gráfico 3, o qual questiona se os discentes veem algum risco associado à prática de reutilização do óleo de cozinha, grande parte deles reconhecem os riscos como redigiu dois desses alunos:

Aluno 6 -"Sim, porquê o óleo ele perde suas vitaminas, e pode aumentar o colesterol ruim";

Aluno 7 - "Sim, porque o óleo fica um pouco escuro e acho que ele prejudica em algo, mas não tenho ideia em quê!’”.

Os outros estudantes afirmaram que não veem problema nenhum em reutilizar, pois como afirma este aluno:

Aluno 8 - "Não, supernormal na minha casa sempre foi assim".

Gráfico 3 - Você vê algum risco associado a essa prática? Explique. Fonte: Própria.

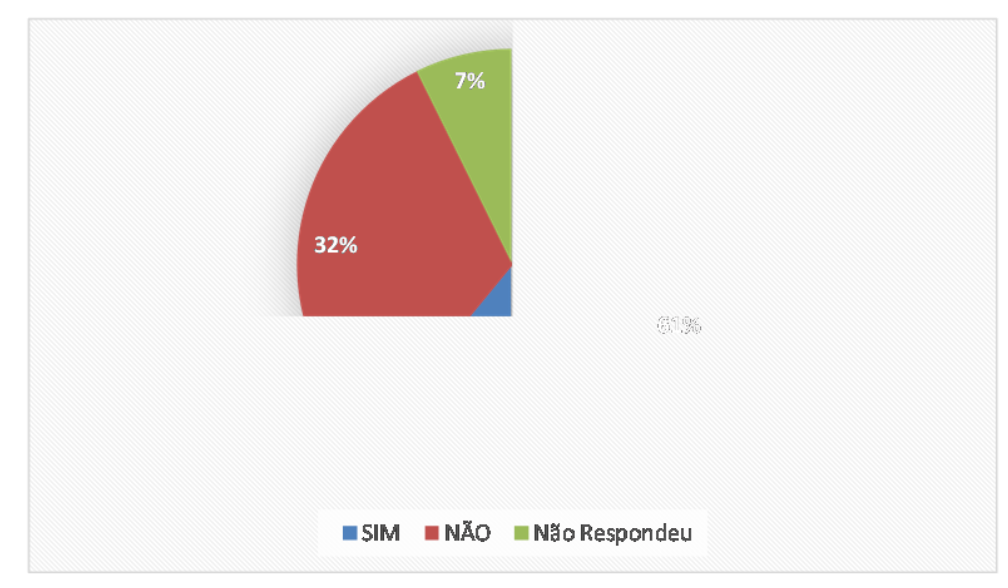

Segundo Sanibal (2014), durante o processo de fritura, os óleos são consecutivamente expostos a diversos fatores que levam a uma grande diversidade de reações químicas, como: hidrólise, oxidação e polimerização da molécula do triacilglicerol. E ainda, os óleos perdem antioxidantes, tocofenolácidos, sofrendo severas transformações químicas e físicas, como aumento da viscosidade, cor do óleo e odor desagradável. (COSTA NETO; FREITAS, 1996).

Em debates sobre esse mesmo ponto em sala de aula (Figura 1), notou-se diversas dúvidas a respeito dos benefícios que os óleos vegetais trazem para o organismo humano. Desta forma, utilizou-se um texto intitulado "Óleo pode ter gorduras boas para o corpo, mas excesso faz mal à 
saúde" e também um vídeo* do médico Dráuzio Varela. O intuito era que os estudantes compreendessem a importância que o óleo possui para o corpo, não só o tendo como maléfico.

Figura 1- Momento de discussão em sala. Fonte: Própria.

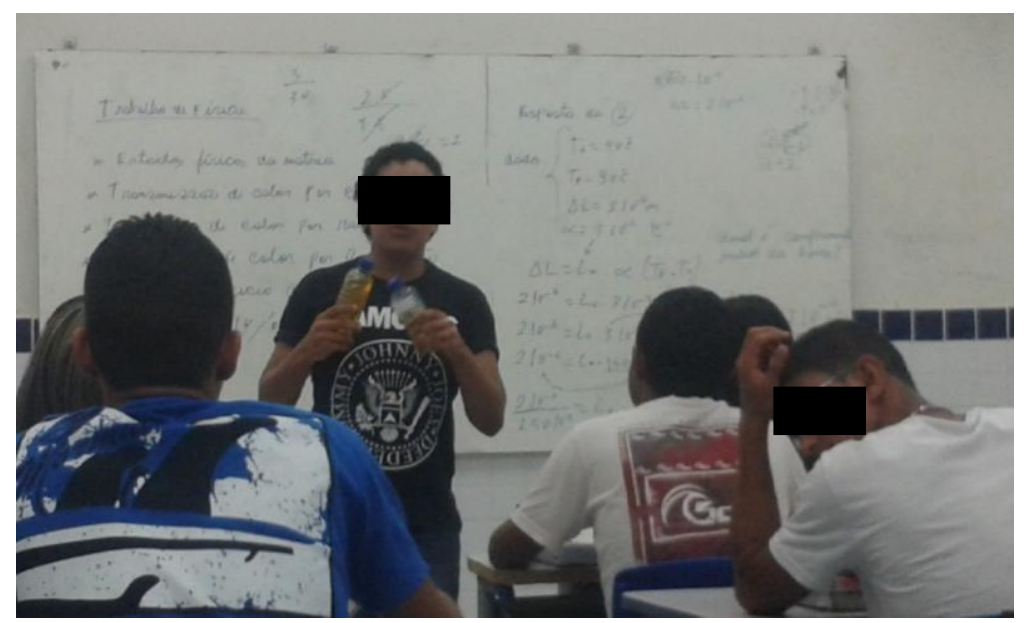

Temáticas que envolvam uma participação ativa e uma criticidade ativa dos alunos, corroboram para uma conscientização ambiental e uma construção de conhecimento mais efetiva, pois BRASIL (2002) afirma que, o Ensino de Química necessita, desse modo, possibilitar o indivíduo a realizar sua análise crítica a respeito do seu lugar no mundo e avaliar o significado de desenvolvimento sustentável e as formas de manejá-lo, estabelecendo assim, uma sociedade mais inteirada com os acontecimentos. Todavia, o ensino de Química é essencial no processo de assimilação do conhecimento indispensável para que se compreendam os alicerces da Educação Ambiental.

O Gráfico 4 expressa a prevalência de quatro destinos preferenciais para o descarte do óleo: a) diretamente na pia; b) no solo; c) adicionado ao lixo úmido; d) doado para terceiros para fabricação de sabões.

Gráfico 4 - E o descarte do óleo de soja, como você faz? Fonte: Própria.

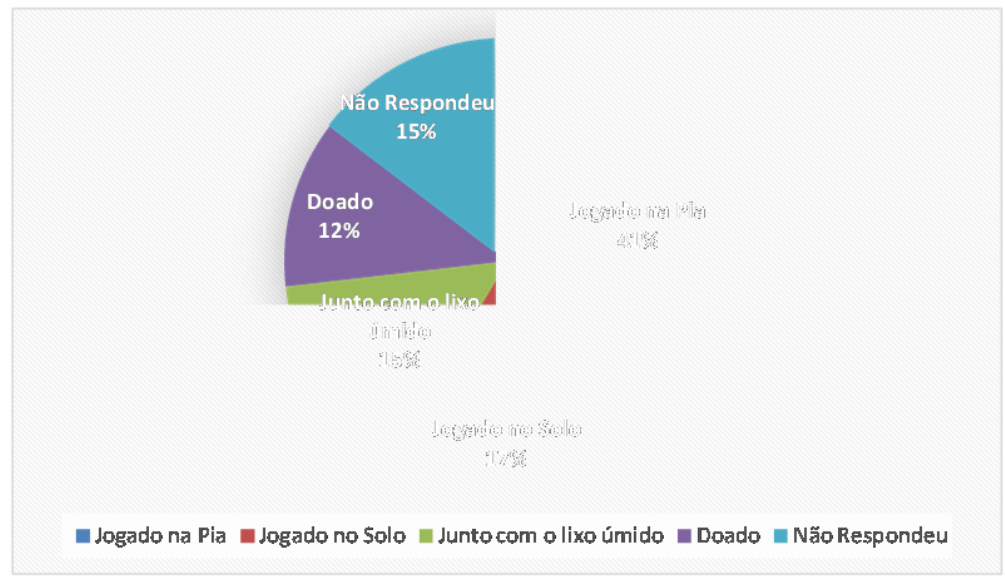

* https://www.youtube.com/watch?v=3ji3qU5licg 
Pôde-se notar que a maioria dos discentes joga o óleo na pia, e praticamente o mesmo percentual descarta-o juntamente ao lixo úmido e no solo. Além disto, apenas $12 \%$ do óleo é doado para produção de sabões.

Em concernência ao Gráfico 5, o qual indaga se os discentes compreendem os danos que podem ser causados à sociedade e ao meio ambiente caso o rejeito de óleo seja lançado no esgoto, foi notado que mais de $50 \%$ do alunado conhece os riscos associados a está prática. Porém, o que alarma nesses dados é que $39 \%$ dos alunos não tem conhecimentos das consequências que podem ser ocasionadas ao meio ambiente.

\section{Gráfico 5 - O rejeito de óleo vegetal lançado no esgoto comum acarreta danos a sociedade e principalmente ao meio} ambiente, você sabia disso? Fonte: Própria.

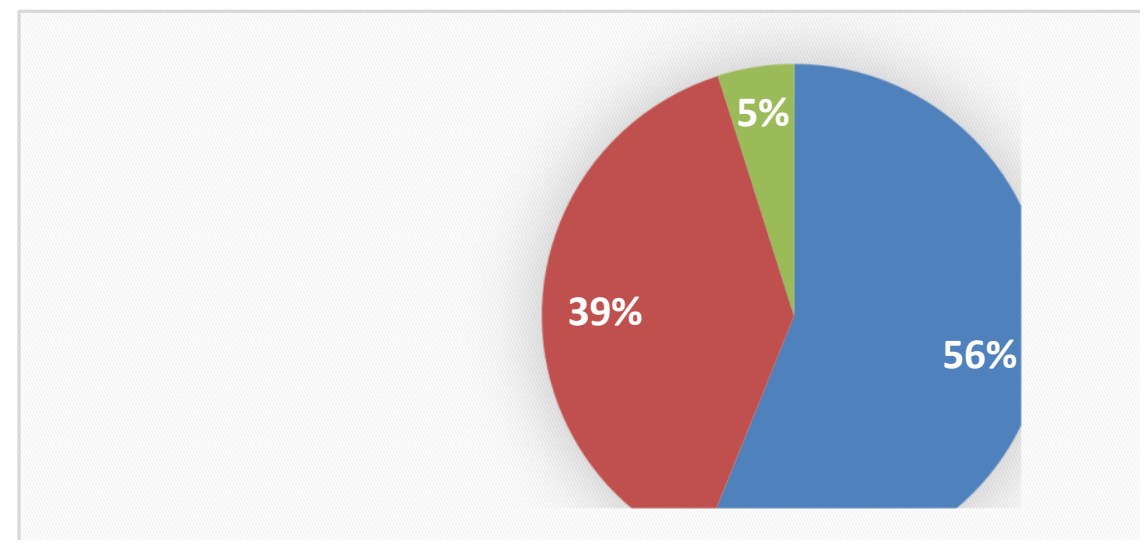

Houve uma discussão em sala, em que foi possível observar os discursos dos estudantes sobre essa problemática. Um deles afirmou:

Aluno 9 - "Não, até porque não somos informados sobre os danos que causa quando isso acontece”.

Assim, é necessário que se desenvolvam atividades com foco nas problemáticas ambientais, pois "contribuem para formação de cidadãos conscientes, aptos para decidirem e atuarem na realidade socioambiental de um modo comprometido com a vida, com o bem-estar de cada um e da sociedade, local e global". (BRASIL, 2002, p. 187).

Na questão 6 do questionário supramencionado (Anexo I), todos os discentes desconhecem programas de coleta de resíduos em sua cidade. Apenas $12 \%$ afirmaram que guarda o óleo utilizado para doar a familiares e a vizinhos para que possam reutilizar produzindo sabões. Já na questão 7 , cerca de $65 \%$ afirmaram que não conhece uma outra forma de reaproveitamento do óleo, a não ser a de fazer novas frituras. E ainda, aproximadamente 35\% dos alunos remanescentes, alegaram que o óleo poderia ser reutilizado para fabricação de sabões e detergentes caseiros, um estudante citou um exemplo em sala: 
Aluno 10 - "O hotel onde minha mãe trabalha o óleo é reaproveitado para fazer detergente e sabão também”.

$\mathrm{Na}$ discussão, foi enaltecido que o reaproveitamento do óleo para produção de sabões e detergentes, gera também benefícios para o meio ambiente e para a economia (gerando uma nova fonte de renda para população).

\section{Conclusões}

Essa atividade conseguiu demonstrar que o consumo consciente do óleo vegetal no preparo de alimentos, gera uma qualidade de vida mais saudável e, ainda, ao se fazer um descarte adequado do óleo reutilizável, atingiu-se uma conscientização ambiental nos discentes. Além disso, ao transformá-lo no produto final sabão, pôde-se propiciar uma forma rentável e barata de ganhar dinheiro.

Destarte, é imprescindível que se trabalhe este tipo de temática em sala de aula tão pertinente ao cotidiano dos alunos, pois apesar das discussões sobre o reaproveitamento do óleo terem ultrapassado fronteiras, percebe-se ainda que há várias lacunas no entendimento do alunado.

Contudo, o Ensino de Química pode contribuir efetivamente na promoção da Educação Ambiental, no sentido de fazer com que os discentes compreendam os problemas ambientais tanto do ponto de vista social, como em decorrência da Ciência Química. Assim, é necessário que a Educação Ambiental concomitantemente a conteúdos químicos estejam cada vez mais presentes nas escolas, para que se trabalhem em cima de campanhas, aliadas ao planejamento e prática de ações ambientais, como por exemplo, o recolhimento do óleo utilizado pela comunidade escolar para reutilizá-lo na produção de sabões e detergentes para todos os envolvidos.

\section{Referências}

BRAGA, I. A. Lixo que vira limpeza e renda. Emprego, renda, sabão ecológico e até combustível vão embora pelo ralo, junto com o óleo que já foi usado em frituras na cozinha. 2007. Disponível em: 〈http://planetasustentavel.abril.com.br/noticia/lixo/ conteudo_260611.shtml〉. Acesso em: ago. 2015.

BRASIL.Ministério da Educação - Secretaria de Educação Média e Tecnológica. Parâmetros Curriculares Nacionais: Ensino Médio: Ciências da Natureza, Matemática e suas Tecnologias. Brasília: MEC/SEMTEC, 1998. 
. LEI N ${ }^{0}$ 9.795, de 27 de Abril de 1999. Institui, no âmbito federal, institui a Política Nacional de Educação Ambiental e dá outras providências. Disponível em: <http://www.planalto.gov.br/ccivil_03/leis/19795.htm >. Acesso em: 5 set. 2015.

. Ministério da Educação - Secretaria de Educação Média e Tecnológica. Parâmetros Curriculares Nacionais: Ensino Médio: Ciências da Natureza, Matemática e suas Tecnologias. Brasília: MEC/SEMTEC, 2002.

Ministério da Educação - Secretaria de Educação Média e Tecnológica. Orientações curriculares para o Ensino Médio: Ciências da Natureza, Matemática e suas Tecnologias. Brasília: MEC/SEMTEC, 2002.

. Ministério da Saúde. Organização Pan--Americana de Saúde. Guia alimentar para a população brasileira: promovendo a alimentação saudável. Brasília, 2006. 210p.

Programa Nacional de Integração da Educação Profissional com a Educação Básica na Modalidade de Educação de Jovens e Adultos. Educação Profissional Técnica de Nível Médio, Ensino Médio: Documento Base. Brasília: MEC: 2009.

CRESPO, Miguel Ángel Gómez; POZO, Juan Ignácio. A aprendizagem e o Ensino de Ciências. Do conhecimento cotidiano ao conhecimento científico. 5a Edição. Porto Alegre: Artmed, 2009.

COSTA NETO, P. R.; FREITAS, R. J. S. Boletim CEPPA. 1996.

ECÓLEO. No Brasil consome-se cerca de 19 litros per capita de óleo por ano, 2013. (Abiove). Disponível em: <http://www.ecoleo.org.br/reciclagem.html>. Acesso em: ago. 2015.

FANTÁSTICO. Drauzio Varella fala sobre frituras na alimentação. Disponível em: < https://www.youtube.com/watch?v=3ji3qU5Iicg>

LIMA, J. R.; GONÇALVES, L. A. C. Anais do simpósio sobre qualidade tecnológica e nutricional de óleos e processos de frituras. Sociedade e Gorduras, SP, p. 144, 1997.

OLIVEIRA, Maria Marly de. Como fazer pesquisa qualitativa. 2. ed. Petrópolis, RJ: Vozes, 2008.

SANIBAL, E. A. A. Alterações físicas, Químicas e Nutricionais de óleos submetidos ao processo de fritura. Caderno de Tecnologia de Alimentos \& Bebidas. 2014.

SASSI, J. S., LINDEMANN H. R. Horta escolar: reflexões a partir de pesquisas da área de Ensino de Ciências e Biologia. IX Encontro Nacional de Pesquisa em Educação em Ciências. 2013.

SEVERINO, A. J. Metodologia do trabalho científico. 23a edição. São Paulo: Cortez, 2008.

TEIS, D. T.; TEIS, M. A. A Abordagem Qualitativa: a leitura no campo de pesquisa, 2013. Disponível em http://www.bocc.ubi.pt. Acesso em: Ago. 2015. 
SILVA, K. S.; NASCIMENTO, M. C. M.; BRASILEIRO, R. M. O. Propostas metodológicas para o ensino de química: reflexões sobre o PIBID e as aulas experimentais na escola pública. In: ENCONTRO INTER-REGIONAL NORTENORDESTE E CENTRO-OESTE DE FORMAÇÃO DOCENTE PARA A EDUCAÇÃO SUPERIOR, 4., 2012, Uberlândia. Anais ... Uberlândia: UFU.

TOMASI, K. Perfil de consumo e descarte de óleo comestível no município de Ijuí-RS. Revista Contexto \& Saúde, Ijuí. V. 14 nº 27, 2014. 


\section{ANEXO I}

1. É comum em nossos lares utilizarmos óleo vegetal (óleo de cozinha) na preparação de determinadas refeições. Qual o consumo do óleo em sua casa?
( ) Nunca
( ) Parcialmente
( ) Raramente
( ) Sempre

2. Você reaproveita o óleo de soja (usado) para mais de uma fritura?

3. Você vê algum risco associado a essa prática?

4. E o descarte do óleo de soja, como você faz?

5. O rejeito de óleo vegetal lançado no esgoto comum acarreta danos a sociedade e principalmente ao meio ambiente, você sabia disso?

6. Você conhece algum programa de coleta de resíduos, em sua cidade ou alguma outra cidade que já morou em que se faz coleta seletiva do óleo de soja?

7. Você conhece alguma forma de se fazer reaproveitamento do óleo de soja (que não seja fazer novas frituras)? 